\title{
Exploring Ways of Using Facebook and Instagram in Teaching English
}

\author{
Hadna Suryantari \\ Applied Linguistic Department \\ State University of Yogyakarta \\ Yogyakarta, Indonesia
}

\author{
Joko Priyana \\ English Education Department \\ State University of Yogyakarta \\ Yogyakarta, Indonesia
}

\begin{abstract}
Nowadays, the use of social media platforms becomes more popular for students. Social media is a web-based platform which permits the users to interact, communicate, and collaborate to others. This changes learning environment as social media gives easy and flexible feature. It is easy to use and easy to access. The feature and flexible use are found as the main reason why social media is a great media in language teaching. Among popular social media platforms in the world, Facebook and Instagram belong to social media which mostly used by people. Through Facebook and Instagram, users enable to share, post, and comment photos, videos, and reading text posted by other users. By sharing and commenting on these social media platforms, students' social networking practices are strengthened automatically. Using Facebook and Instagram provides great opportunities to improve English language teaching and learning process in and beyond the classroom. Teachers can develop the activities by utilizing these social media platforms creatively. Thus, students will feel more motivated toward English learning. This paper will give an overview of the main advantages of using Facebook and Instagram and explore activities how to use these social media platforms in English language teaching and learning practice.
\end{abstract}

Keywords—social media; facebook; instagram; teaching media; teaching activities

\section{INTRODUCTION}

The emergence of mobile technologies is now a common phenomenon in our daily life that changes learning environment. One of the mobile technologies is social media platform which is mostly used by students and adolescents for various aims especially on social needs [1]. Social media is defined as a web-based service which permits individuals to construct a public or semi-public profile within a bounded system, articulate a list of other users with whom they share connection, and view and traverse their list of connections and those made by others within the system [2]. By using social media, students can hold collaboration and interaction to others [3] such as sharing, exchanging, commenting, discussing, and creating knowledge and information. Since the features, social media platforms can be used as teaching and learning tool in nowadays era, especially in English language teaching and learning.
There are numerous social media platforms. Some of them are Facebook and Instagram. In Indonesia, those social media platforms belong to the big-four of the most used social media platforms in 2017 and most of the users are adolescents and young adult (WeAreSocial.net \& Hootsuite). These social media platforms have similar features that enable the users to share, comment, discuss, and create knowledge and information in the forms picture, video, and reading text. By using these social media, students have many chances to practice English either passively or actively. It shows that Facebook and Instagram is appropriate media in teaching and learning language. Thus, this paper would like to give an overview about Facebook and Instagram including activities which can be conducted in English language teaching and learning.

\section{LITERATURE REVIEW}

\section{A. Facebook}

Facebook was designed by Mark Zuckerberg, a Harvard student, and his classmates in 2003. It was launched in 2004 [4]. As an online interaction mean, Facebook can also be used to share users' various activities, look for friends, upload photos and videos, and write status or thought on the Facebook wall. Generally, Facebook has specific features which are usually used by users. The features are as the following.

- Timeline: This feature consists of users' personal activity on facebook including memories and information of users.

- Status update: This is used to share a status to facebook friends. Users can communicate their recent activities, post a link, tag or mention who they want to include in a conversation, and share photos, videos, and thoughts.

- Likes: "Like" button is found near every piece of facebook content such as status update, photos, videos, comments, brand timelines, apps, and ads. By liking something, users can their support to the status.

- Comment: It is used to respond a post by the page or by another fan with the "write a comment” box. 
- $\quad$ Shares: Users can share content from another post on their own page by using the "share" feature.

- $\quad$ Fans: Facebook users who join a page as they have a particular interest in the topic or a connection with the product.

By features offered above, Facebook can be used as English language teaching and learning media. It is a great English learning practice place since most of its features are set in English, so that the users, especially students, are required to have sufficient knowledge in English to maximize the use of Facebook [5]. Moreover, Facebook provides an alternative to real life classroom since it give chances to the students to actively and regularly participate through Facebook as inside classroom [6]. By participating, students' sense of community in language classroom is raised since Facebook creates the scope to improve language students' socio-pragmatic competence especially while being with peers [7, p. 17].

In relation to language skill enhancement, Facebook can be used as a learning and teaching media to improve students' reading skill if students get chance to discuss assignment, ask, answer questions, post information, and support one another in Facebook [8, p. 34]. Moreover, utilizing Facebook in teaching and learning writing can also enhance students' writing skill as students do not feel encouraged to do writing activities as they find Facebook writing as communication [5]. Unintentionally, it can also give students opportunity to use both scaffolding and schemata as a result engagement with peers [6]

\section{B. Facebook Activities in English Language Teaching and Learning}

There are various language teaching and learning which can be conducted by utilizing Facebook. The following are activities list which can help students to improve their four major skills in English.

\section{1) Listening activities}

a) Listening in flipped classroom: Listening activity in flipped classroom utilizing with facebook was conducted by Roth \& Suppasetseree [9]. In this activity, teacher asks and discusses some questions related to the topic with the students. Then, students are directed to watch video set with authentic American spoken English and practice posted on facebook goup. In the classroom, teacher guides students to discuss the video in groups. By this activity, students are encouraged more to ask any question face-to-face since they can improve their listening comprehension by sharing their knowledge with others. After sharing their knowledge about the videos, students are directed to make summary about the video. Indirectly, this activity improves also students' speaking and writing skill.

b) Communicative listening: Listening is usually seen as a passive skill. By this communicative listening activity, Ovalle, Arevalo, \& Castellanos [10] created listening activity in communicative approach context. The activity is started by led students to watch video posted on facebook by considering to topic and context first. Through this activity, students listen to good pronunciation and sounds production. Then, teacher and students discuss the topic and keywords related to the second video. While watching the second video, students are directed to listen sincerely, identify keywords, and pay attention to the main idea. In the end of listening class, teacher asks students about the topic based on their background knowledge.

2) Speaking activities:Speaking is closely related to listening skill as interconnected ways of accomplishing communication. Every speaker is simultaneously a listener and every listener is at least potentially a speaker (Orphandy, and EL Menoufy as cited in Nurmy [11]). The role of facebook in students' speaking skill can be seen when they make friends with people from overseas or watching video in English language provided in their or their friends' account [11]. It means that speaking activity through facebook unconsciously has also be conducted in listening activities if the activity requires students' speech production to communicate to other.

\section{3) Reading activities}

a) Extensive reading:Using facebook in extensive reading in English teaching and learning activities was conducted by Boonkit [12]. In this activity, students are introduced to an extensive reading activity performed outside of classroom. Facebook is used as discussion place for students to share their reading topics, reading strategies, and what they learn from their reading in real world context. This activity is considered as one way of encouraging EFL students to use their four integrated English skills in real world communication. Each student, then, is encouraged to read topics in real world English and they can invite their Facebook friends to post their reflection and to share reading ideas, strategies, and new vocabulary. The teacher is also invited to read and give comments on each student's reading topics. In this activity, teacher should encourage students to feel comfortable when posting topics.

b) Facebook group discussion:Improving reading strategies by using facebook group discussion was conducted by Rahayu [13]. In this activity, teacher is required to create a group discussion on Facebook. In this group, teacher shares a link and students have to open and read it. Teacher posts a question and asks the group to discuss the answer in the form of comments which can be a direct response to the question, a request clarification. Shortly, there are ways to get the correct answer. In a text, teacher should prepare some questions. Teacher plays role as a judge for comment posted by the group members. At random teacher asks for student to post a link.

\section{4) Writing activities}

a) Using Facebook notes as medium of providing peer feedback: The writing activity, proposed by Yusof, AbManan, \& Alias [14], involves the process of planning, drafting, revising, and editing. Guided peer feedback via Facebook notes can assist the teacher in making sure all students of the students writing chunks are reviewed at four stages of writing process and improve their written works quality. The use of Facebook notes as medium providing peer feedback is set at 
the planning stage of writing that is outlining. Through this activity, students are able to provide constructive feedback to their peers. The suggestion and comments posted on the facebook notes are found useful in helping their peers to develop the outlines and first draft. In this activity, it is important that English teachers should give students guidance during the writing process.

b) Using Facebook group: There are numerous researches toward the use of facebook group in writing activities. One of them is conducted by Melor, Salehi, Sun, Yen, \& Li [15]. In his research, he utilized Facebook after all of the students accomplished their writing in groups. In facebook group, each group had to present their writing work about argumentation text, at least two groups in a week. The other groups that did not have presentation had to give comments toward the presented writing works.

\section{Instagram}

Instagram was created by Kevin Systrom and Mike Krieger. Then, it is developed by Facebook and launched on October 2010. This social media platform permits the users to share photos and 60 -second video that can be edited with numerous filters organized with users tags and location information, add caption, like the content, add comments, browse and follow other accounts, check a feed generated by followed accounts, and search for hastags and users. Mainly there are a number of features of Instagram which can be used by the users. Those are as the following.

- Instagram profile interface: It shows the user's information such as biography profile photo, posts, and follower/ following account of the user.

- Profile content: It consists of all profile photos. Viewers can click the photos to display them obviously.

- Instagram's photo content: By clicking on the photo or videos, viewers can give "like" and comment, read previous comments based on the photos or videos. This feature also display many "like" and comment under the caption.

- Navigational tool: This feature consists of five icons at the bottom of each instagram's screen. The icons are home page, explore page, posting page, notification page, and navigational tool.

By the features above, students can exchange views and opinion of various topics. They can also actively participate in commenting photos or videos. Therefore, exchanging of opinion and ideas between students and teacher are possible. Instagram, a website providing photos and videos sharing, taking and editing pictures, place to give caption, comment and feedback, can encourage students to be spatially and linguistically aware [16]

Moreover, Ali [17] states several reasons why Instagram is a great media in English teaching and learning activities. First, Instagram provides visual data which support aid in language classrooms. Second, Instagram gives chances to the students to socialize and communicate each other out of classroom context. Then, Instagram is one of social media platform which generally used by students at adolescent and young adult age. Lastly, Instagram offers easy and simple access for in the classroom and beyond language classroom use.

\section{Instagram Activities in English Language Teaching and Learning}

There are various language teaching and learning which can be conducted by utilizing Instagram. The following are activities list which can help students to improve their four major skills in English.

1) Listening activities: In listening activity, Hudson [18] suggests listening to English native speakers activity. Teacher posts a video(s) which can be a short song, movie chunks, or short conversation. Students, then, are directed to watch the video(s) and they have to answer questions based on the video(s) provided by the teacher.

2) Speaking activities

a) Capturing field trip memory: This activity proposed by Ali [17]. Students are directed to post their holiday photos and give hastag which is never used before by other users. Students have to choose five photos as material in preparing their two-minute presentation. These pictures series are useful in assisting them to present and construct recount text well.

b) Reviewing a famous person: This activity is suggested by Hudson [18]. This activity is a good way to teach descriptive text. Teachers have to use instagram to view their students' posts related to famous persons. Then, in the classroom, the teacher asks students to describe one or two thing about the famous person as the appearance.

\section{3) Reading activities}

a) Creating book trailers: This activity is created by Ferlazzo [19]. The students have to create a short video about fifteen seconds and attract their friends' curiosity about the book. The video should consist of the title, author, short book content in a sentence, favourite quote based on the book, and how many "like" other students will give.

b) Sharing reading recommendation: This activity proposed by Hudson [18]. In this activity, teacher asks students to snap their favourite book photos and review the photos at least in a sentence to five sentences in the caption. Other students are asked to give opinion and comment toward their classmates' posts.

\section{4) Writing activities}

a) Captioning photos: This activity is designed by Spencer [20]. In this activity, teachers have to post an attractive photo. Students are assigned to give captions related to the photo in comment column. In order to be more complicated, teachers can require the use of various parts of speech, phrases, even clauses. The best caption will get a reward.

b) Inspiring photo: This activity is also designed by Spencer [20]. By this activity, teachers need to post an 
inspiring photo and gives students questions related to the photo. Students have to comment and share their opinion about the photo. This activity can help students in composing writing task and encourage them to develop ideas in writing.

\section{CONCLUSION}

Since social media platforms grow rapidly, possible ways to convey teaching material have also advanced. Facebook and Instagram as social media platforms provide advantageous effect in English language teaching and learning practice. These platforms help teachers to involve students on language learning either inside or outside of the classroom. Moreover, the use of Facebook and Instagram can also be simply designed in individual, pairs, and small groups to let students work together practicing their English. Integrating Facebook and Instagram in teaching and learning process offers joy learning experience to students. Thus, it is important to develop interesting learning activities by utilizing these social media platforms. Lastly, it can be underlined that utilizing Facebook and Instagram in English as foreign language learning can be great innovative and effective media since they are used by teachers and students for educational purposes properly.

\section{REFERENCES}

[1] M. M. Yunus, H. Salehi, and C. Chenzi, "Integrating Social Networking Tools into ESL Writing Classroom: Strengths and Weaknesses,” Engl. Lang. Teach., vol. 5, no. 8, pp. 42-48, 2012.

[2] D. M. Boyd and N. B. Ellison, "Social Network Sites: Definition, History and Scholarship," 2006. [Online]. Available: http://mimosa.pntic.mec.es/mvera1/textos/redessociales.pdf. [Accessed Mar. 16, 2011].

[3] T. T. Goh, B. C. Seet, and N. S. Chen, "The impact of persuasive SMS on students' self-regulated learning,” Brit. J. of Edu. Technol., vol. 43, no. 4, pp. 624-640, 2012. DOI: 10.1111/j.1467-8535.2011.01236.x.

[4] B. Stone, "Web of Risks,” Newsweek, August 21, 2006, p. 76.

[5] M. K. Kabilan, N. Ahmad, and M. J. Z. Abidin, "Facebook: An online environment for learning of English in institutions of higher education?” Intern. and Higher Edu., vol. 13, no. 4, pp. 179-187, 2010.

[6] M. M. Hasan, and N. A. Labonya, "Using Facebook in ELT: Higher secondary teachers’ perspective in Bangladesh,” European American J., vol. 4, no. 9, pp. 86-100, 2016.
[7] G. Blattner, M. Fiori, "Facebook in the language classroom: Promises and possibilities,” Instruct. Technol. and Distan. Learn. (ITDL), vol. 6, no. 1, pp. 17-28, 2009.

[8] H. Haverback, "Facebook: Uncharted territory in a reading education classroom,” Read. Toda., vol. 27, no. 2, p. 34, 2009.

[9] C. Roth and S. Suppasteseree, "Flipped classroom: Can it enhance English listening comprehension for pre-university students in Cambodia?” Learning in and beyond the Classroom: Ubiquity in Foreign Language Education, 2016, pp. 255-264.

[10] A. M. Ovalle, K. M. P. Arevalo, and L. J. G. Castellanos, "Facebook: Methodological strategy to enhance listening in English in 4th grade at Antonio Narino High School night shift,” Bachelor thesis, The Univ. of Libre, Bogota, Colombia, 2014. [Online]. Available: http://repository.unilibre.edu.co.

[11] A. R. Nurmy, "Facebook as a medium in English learning as foreign language at IAIAN Pontianak,” At-Turats, vol. 11, no. 1, pp. 48-57, 2017.

[12] K. Boonkit, "Facebook: Bridging the gap between classroom English and real world reading for non-native learners of English,” Int. J. of Arts \& Sci., vol. 4, no. 18, pp. 207-225, 2011.

[13] E. Y. Rahayu, "The used of facebook group discussion to improve reading strategies: An action research,” Dinam. Baha. dan Ilmu Bud., vol. 9, no. 2, pp. 78-87, 2014.

[14] J. Yusof, N. A. AbManan, and A. A. Alias, "Guided peer feedback on academic writing tasks using Facebook notes: An exploratory study," presented at The 3rd International Conference on ELearning ICEL 2011, Bandung, Indonesia. Procedia Social and Behavioral Sciences, vol. 67, pp. 216-228, 2012.

[15] M. D. Y. Melor, H. Salehi, C. H. Sun, J. Y. P. Yen, and L. K. S. Li, "Using Facebook groups in teaching ESL writing," Recent Res. in Chemist., Biol., Env. and Cultu., vol. 75, no. 1, pp. 75-80, 2012.

[16] J. Phillips, "Using Instagram in an educational context," 2013. [Online]. Available: http://www.emergingedtech.com/2013/02/using-instagramin-an-educational-context/. [Accessed Jun. 1, 2017].

[17] S. A. Ali, "Embracing the selfie craze: exploring the possible use of instagram as a langugae learning tool.” Issu. and Tren. in Edu. Technol., vol. 2, pp. 1-16, 2014

[18] H. Hudson, “10 ways to use Instagram in the classroom,” 2013. [Online]. Available: http://www.weareteachers.com/comunity/blogs/. [Accessed May 29, 2017].

[19] L. Ferlazzo, “Students Making Video “Book Trailers,” 2011. [Online]. Available: http://larryferlazzo.edublogs.org/2011/05/31/studentsmaking-video-book-trailers. [Accessed Jun. 1, 2017].

[20] J. Spencer, “Ten ideas for using Instagram in the classroom,” 2012. [Online]. Available: http://www.educationrethink.com/2012/07/tenideasfor-using-instagram-in.html. [Accessed Jun. 1, 2017]. 